\section{Low back pain}

\section{Related to emotional disorder}

EDITOR,-Andrew Frank's review of low back pain pays insufficient attention to the importan role of anxiety and depression in the genesis and maintenance of pain. ${ }^{1}$ No guidance is given for detecting a clinically important degree of emotional disorder. Although some of the emotional consequences of low back pain are listed, there is insufficient discussion of the management of these important components of pain.

The relation of emotional disorder to pain syndromes is a complex issue ${ }^{2}$ and much will depend upon the definition of the emotional state: for instance, chronic physical ill health will lead to demoralisation and loss of capacity will lead to grief, but these are not the same states as the type of mood disorder which is likely to respond to antidepressant drugs. ${ }^{3}$ I have recently argued that anhedonia is the best clinical marker for response to such prescription. ${ }^{4}$

The hospital anxiety and depression scale ${ }^{s}$ is a brief self assessment scale which distinguishes between the concepts of anxiety and depression and avoids emphasis on somatic symptomatology; the depression subscale rests largely on the anhedonic state and a high score on this component of the scale will provide the practitioner with some guidance regarding treatments. The hospital anxiety and depression scale is now available from NFER-Nelson, Darville House, 2 Oxford Road East, Windsor, Berkshire SL4 IDF.

R P SNAITH

Academic Unit of Psychiatry,

St James's University Hospital,

Leeds LS9 7TF

Frank A. Low back pain. BMF 1993;306:901-9. (3 April.)

2 Schulberg HC, McClelland M, Burns BJ. Depression and physical illness: the prevalence, causation and diagnosis of comorbidity. Clin Psychol Rev 1987;7:145-67.

3 Snaith RP. The concepts of mild depression. $\mathrm{Br} \mathcal{O}$ Psychiatry 987;150:387-93.

4 Snaith P. Anhedonia: exclusion from the pleasure dome. $B M$ 1993;305:164.

5 Zigmond A, Snaith RP. The hospital anxiety and depression scale. Acta Psychiatr Scand 1983;67:361-70.

\section{Consider compromised blood supply}

EDITOR, - Andrew Frank stated that "up to $85 \%$ of patients with low back pain cannot be given a definitive diagnosis because of the poor associations between symptoms, signs, imaging results, and pathological findings." "A few pages further on in this issue of the $B M F$ an advertisement for a handbook of vascular diseases said that "vascular problems are common-so much so that they are often forgotten and sometimes overlooked."

Vascular diseases are overlooked as one potential reason for low back symptoms. The lumbar spine receives its blood supply from the paired lumbar arteries and from the middle sacral artery, which originate from the posterior wall of the abdominal aorta. ${ }^{2}$ The first atherosclerotic changes commonly occur in this part of the aorta, and atheromatous lesions most commonly form around orifices of branches and bifurcations of the artery. ${ }^{3}$ Consequently it can be assumed that the lumbar arteries, and especially the middle sacral artery, which has its orifice in the bifurcation, may become affected early in adult life.

To explore the condition of the arteries supply-

\section{Advice to authors}

Priority will be given to letters that are less than 400 words long and are typed with double spacing. All authors should sign the letter. Please enclose a stamped addressed envelope for acknowledgment.

ing the lumbar spine in subjects with and without low back pain, I evaluated 100 postmortem lumbar aortograms and compared the findings with history of low back symptoms during life. Subjects with a lengthy history of low back pain showed on average 2.02 entirely missing arteries and 1.43 narrow ( $\leqslant 50 \%$ in diameter) arteries compared with age matched controls, who had $\mathbf{0 . 8 8}$ missing arteries $(p<0.001)$ and 0.61 narrow arteries $(p<0.001)$ The study indicated that insufficient arterial blood flow, owing to either atheromatous lesions in the abdominal aorta or congenital hypoplasia of the arteries, may be an underlying factor for low back symptoms. The original article covering evaluation of 56 aortograms was published in April 1993.

Further studies on the relation between atherosclerotic changes in the abdominal aorta and disc degeneration showed that disc degeneration increased with advanced atherosclerotic manifestations in the abdominal aorta, and especially with stenosis of the ostia of segmental arteries above and below the disc.

Customary methods of investigating the lumbar spine do not show its blood vessels, and little is known about their condition in patients with low back disorders. I would like to remind doctors investigating and treating such patients to conside that vascular problems are common-and may even be one of the underlying factors for low back symptoms now labelled non-specific.

Department of Forensic Medicine,

LEENA I KAUPPILA

University of Helsinki,

PO Box 40,

SF-00014 Helsinki,

Finland

Frank A. Low back pain. BMY 1993;306:901-9. (3 April.)

2 Chiras J, Morvan G, Merland JJ. Angiographie normale des arteres inter-costales et lombaires: systematisation des branches parietales avec confrontation anatomique. I Neurorad 1979;6: $169-96$.

3 Ross R. Atherosclerosis. In: Wyngaarden JB, Smith LH, eds. Cecil textbook of medicine. Philadelphia: Saunders, 1988: 318-23.

4 Kauppila LI, Tallroth K. Postmortem angiographic findings for arteries supplying the lumbar spine: their relationship to lowback symptoms. F Spin Dis 1993;6:124-9.

5 Kauppila LI, Penttilä A, Karhunen PJ, Lalu K, Hannikainen P. Lumbar disc degeneration and atherosclerosis of the abdominal aorta. Spine (in press).

\section{Abnormalities rare on $\boldsymbol{x}$ ray examination}

EDrToR, - Although Andrew Frank recognises the "poor associations between symptoms, signs, imaging results, and pathological findings" he nevertheless reproduces questionable guidelines for radiological investigation of this complaint.

Plain radiography is often used to exclude fractures, neoplasms or congenital anomalies. However, these abnormalities are found only once in every 2500 examinations in patients aged between 20 and 50 years with non-specific back pain. ${ }^{2}$ There is poor correlation between disc narrowing and the size of marginal osteophytes, compared with the degree of disc degeneration. ${ }^{3}$ Furthermore, considerable disc degeneration can be present without radiographic changes. ${ }^{4}$ Computed tomography in asymptomatic individuals can show an appreciable number of abnormalities. ${ }^{5}$ Therefore, its suggested use as a prognostic indicator can only be deprecated.

Reduction in the total radiation dose to the population can be maintained by using radiography only for examinations directed at confirming a diagnosis, rather than as a screening method. ${ }^{6}$

M P GREVITT

Department of Fracture and Orthopaedic Surgery,

University Hospital

Queen's Medical Centre,

Nottingham NG7 2UH

1 Frank A. Low back pain. BMY 1993;306:901-9. (3 April.)

2 Nachemson AL. The lumbar spine: an orthopaedic challenge. Spine 1976;1:59-71.

3 Malmivaara A. Disc degeneration in the thoracolumbar junctional region. Evaluation by radiography and discography in autopsy. Acta Radiol Diagn 1987;28:755-60.

4 Friberg S, Hirsch C. Anatomical and clinical studies on lumbar disc degeneration. Acta Orthop Scand 1949;19:222-42.

5 Wiesel SW, Tsourmas N, Feffer HL, Citrin CM, Patronas N. A study of computed assisted tomography. I. The incidence of positive CAT scans in an asymptomatic group of patients. positive CAT scans in
Spine 1984;9:549-51.

6 Royal College of Radiologists Working Party. Influence of Royal College of Radiologists guidelines on referrals from general practice. BMF 1993;306:110-2. (9 January.)

\section{Prevention better than cure}

EDITOR, - The recent state of the art paper by Andrew Frank has tackled a monumental task in a truly commendable manner. ${ }^{1}$ Reviewing the pathophysiology, diagnosis, differential diagnosis, treatment, and rehabilitation of low back pain of al possible causes on eight pages makes the work of Sisyphus look easy. Even so, one important aspect of low back pain has been excluded totally: prevention.

With a complaint causing as huge an impact on society as low back pain, it seems obvious that prevention should become a key issue. To a great extent prevention means eliminating risk factors. Admittedly, research on risk factors for low back pain is in its infancy, yet regular exercise, reduction of overweight, avoidance of faulty postures and heavy lifting, ${ }^{2}$ as well as stopping smoking, ${ }^{3}$ are all potentially effective measures for primary prevention. Low back pain has become too prevalent for our health systems to be able to cope. Effective prevention and increased emphasis on prevention research may well be one way out of the dilemma.

E ERNST

Department of Physical Medicine and Rehabilitation, University of Vienna (AKH), 1090 Vienna,

Austria

1 Frank A. Low back pain. BMY 1993;306:901-9. (3 April.)

2 Risk factors for back trouble [editorial]. Lancet 1989;i:1305-6. 3 Ernst E. Smoking, a cause for back trouble? $\mathrm{Br} \mathcal{J}$ Rhemato 1993;32:239-42.

\section{Illustration misleading}

EDITOR, - I would like to draw attention to one or two details in Andrew Frank's review of low back pain that might lead readers astray.'

Bed rest for two days is usually adequate for 